\title{
The Relationship between Self-Efficacy and Health Promoting Behaviour among Older Adults with Chronic Illness
}

\author{
Norfidah Mohamad, Zamzaliza Abdul Mulud, Maznah Ibrahim, NurFarzana Damanhuri \\ Centre for Nursing Studies, Faculty of Health Sciences, \\ Universiti Teknologi MARA Selangor, Puncak Alam Campus, Malaysia
}

norfidah@uitm.edu.my, zamzaliza@uitm.edu.my, maz16614@yahoo.com,nfdpanda@gmail.com Tel: +60332584356

\begin{abstract}
Self-efficacy plays an essential role in increasing health-promoting behaviour among older adults with chronic illness. Chronic illness requires high selfefficacy to manage the illness appropriately. Hence, the purpose of this study is to identify the relationship between self-efficacy and health-promoting behaviour among older adults with chronic illness. A cross-sectional study was conducted using a self-administered questionnaire to 218 older adults. The results from this study found a relationship between self-efficacy and health-promoting behaviour exists at rho 0.28 and $p$-value 0.001 . This study revealed that self-efficacy strongly relates to health-promoting behaviour among older adults.
\end{abstract}

Keywords: self-efficacy; health-promoting behaviour; older adults; chronic illness

eISSN: 2398-4287 @ 2019. The Authors. Published for AMER ABRA cE-Bs by e-International Publishing House, Ltd., UK. This is an open access article under the CC BYNC-ND license (http://creativecommons.org/licenses/by-nc-nd/4.0/). Peer-review under responsibility of AMER (Association of Malaysian Environment-Behaviour Researchers), ABRA (Association of Behavioural Researchers on Asians) and cE-Bs (Centre for Environment-Behaviour Studies), Faculty of Architecture, Planning \& Surveying, Universiti Teknologi MARA, Malaysia.

DOI: https://doi.org/10.21834/e-bpj.v4i11.1725

\subsection{Introduction}

Chronic diseases are the most prevalent and costly medical issue worldwide. As increasing in people age, there will be a rise in a number of adults, exposed to the risk of chronic disease, for example, arthritis, cancer, diabetes and heart disease (WHO, 2010). Ageing adults experience a higher risk of chronic disease. $60 \%$ of older adults managed to have more than two chronic illnesses in 2012, and chronic illness will affect daily functioning, quality of life, and independence, increases risk of long-term institutionalization and give high demands on informal caregivers (Ward, Schiller, \& Goodman, 2014).

Although chronic diseases are among the most common and costly health problems, they are also among the most preventable ones. Self-efficacy is an intellectual asset that empowers an individual to adjust and adapt to chronic disease. People with self-efficacy can modify under different conditions and are willing to address new difficulties (Bandura, 1997). Self-efficacy predicts self-care among patients with chronic disease and can result in better medical outcomes and reduce morbidity. For example, patients with low selfefficacy have a higher resistance to treatment in patients with diabetes mellitus (Mishali, Omer, \& Heymann, 2011). Increased age relates to lower self-efficacy, where ageing-related stereotypic beliefs function as a factor lowering self-efficacy, thus decreasing healthpromoting behaviour (Yeom, 2014). Close attention on self-efficacy is needed to improve self-care in chronic illness patient (Daniali, Darani, Eslami, \& Mazaheri, 2017). Individuals with high chronic illness burden tend to have lower confidence in taking care of their health.

A health-promoting behaviour focuses on life improvement through a lifestyle that consists of six elements, which are health responsibility, nutrition, spiritual growth, physical activity, stress management and interpersonal relations. Older adults with chronic illness perform better in health-promoting behaviour. The increasing level of health-promoting behaviour will increase the level of selfefficacy among patient (Giena, Thongpat, \& Nitirat, 2018). Numerous studies have shown that self-efficacy has a significant impact on

eISSN: 2398-4287 ( 2019. The Authors. Published for AMER ABRA cE-Bs by e-International Publishing House, Ltd., UK. This is an open access article under the CC BYNC-ND license (http://creativecommons.org/licenses/by-nc-nd/4.0/). Peer-review under responsibility of AMER (Association of Malaysian Environment-Behaviour Researchers), ABRA (Association of Behavioural Researchers on Asians) and cE-Bs (Centre for Environment-Behaviour Studies), Faculty of Architecture, Planning \& Surveying, Universiti Teknologi MARA, Malaysia.

DOI: https://doi.org/10.21834/e-bpj.v4i11.1725 
health behaviour. Therefore, to maintain quality of life among patients, this study investigates whether self-efficacy affects changing health-promoting behaviour among older adults with chronic illness.

\subsection{Literature Review}

Self-efficacy refers to an individual's assessments of their effectiveness or competency to perform a specific behaviour successfully Bandura (1994). It is an individual's expectations may vary across behaviours and contexts. In addition to that, health behaviour and health outcomes are a function of two beliefs - efficacy expectations and outcome expectations. An efficacy expectation, or 'perceived self-efficacy', is a judgement of one's capacity to perform a particular behaviour successfully

A study by Yeom (2014) to elderly Korean adults, stated that ageing-related stereotypic beliefs function as a factor lowering selfefficacy as well as decreasing health-promoting behaviours. Self-efficacy conciliates the control of stereotypic beliefs of ageing on healthpromoting behaviours, indicating that ageing decreases self-efficacy, which, in turn, could lead to a lower level of health-promoting behaviours. Based on the study by Scult, et al., (2015) that used the self-efficacy scale as an outcome measures stated that a healthy ageing program appears to be a favourable and advantageous intervention for older adults with the potential to raise the levels of selfefficacy and morale. Self-efficacy and multiple illness representations in older adults suggest that illness-specific descriptions of older people with multimorbidity are a product of both illness-specific and person-level factors, such as self-efficacy. Strengthening individual self-efficacy may improve illness controllability nevertheless of illness-specific information. Whereas a study by Quinn, Khokhar, Weed, Barr \& Gruber-Baldini (2015), stated that older adults had high self-efficacy and high readiness and confidence in their ability to monitor their diabetes when they use diabetes health intervention on a mobile phone that provides educational information to self-manage their diabetes. Older adults with a low level of health education had lower self-management abilities where sex, age, living situation, income, chronic illness, and status of mental health did not affect the association between health education and self-management abilities.

Self-efficacy in dealing with chronic disease is not a simple matter of knowing what to do. It reflects an ability to organize and integrate cognitive, social, and behavioural skills to meet a diversity of reasons. Level of self-efficacy may be contrastive when it comes to chronic disease's people. A study by (Rutten, et al., 2016) on self-efficacy and chronic condition stated that individuals with high chronic illness burden had lower confidence in taking care of their health. In their study, they indicated that patient with positive patient-centred communication would have higher self-efficacy.

Moreover, a study by (Daniali, Darani, Eslami and Mazaheri (2017) about self-efficacy and physical activity stated that although chronic disease patients had a good medication adherence, other self-care behaviours such as physical activity has been ignored and uncared for. They also stated that close attention on psychological factors such as self-efficacy should be considered as a proximal factor to improve self-care in chronic illness patient. Other than that, an essential element for people with chronic illness to increase selfcare activity is self-efficacy.

According to Chenary, Noroozi, Tavafian, \& Firoozabadi (2016), health-promoting behaviour defines an activity that can affect one's health conditions and daily activities derived from environmental, demographical, and social variables. Health promotion gives a positive impact in life, such as can prevent the progression of the disease, decrease burden in condition, improve self-care, reduce functional loss, enhance people's health and increase the quality of life. Besides that, as one grows older, expected that life satisfaction and quality of life decrease not only because of functional insufficiency but also because of chronic illness. Their compliance toward healthpromoting behaviour also decrease. However, in a study by Mofrad, Jahantigh, \& Arbabisarjou (2016), they reported that chronic illness had related to one's lifestyle. In their study, the result shows that older adults who have chronic illness perform better on health-promoting behaviour compared than other older adults.

\subsection{Methodology}

\subsection{Sample}

A cross-sectional study was applied to this research. The proposed study was conducted at UiTM Medical Specialist Centre, Sungai Buloh. Located in Selangor, Malaysia. UiTM Medical Specialist Centre commenced its clinic as well as other inpatient services for the communities in Selangor. Purposive sampling method was chosen for this research with a sample size of 218. Inclusion criteria of this study were (1) older adults age 60 and above; (2) older adults with chronic illnesses such as diabetes mellitus, cardiovascular disease, hypertension, arthritis, chronic obstructive pulmonary disease (COPD), stroke and asthma. Exclusion criteria of this study were bedridden patient.

\subsection{Instruments}

The chosen questionnaire for this research is the Health-Promoting Lifestyle Profile II (HPLP-II) and General Self-Efficacy Scale (GSES), which were adopted by previous research. The questionnaire is divided into three sections. In Section A, the questions are on demographic data of respondents, while Section B comprises of HPLP-II questionnaire of 52 questions summated behaviour rating scale that uses a 4-point response format. The items consist of 6 subscales covering health responsibility, physical activity, nutrition, interpersonal relationship, spiritual growth and stress management. The lowest and highest total score in this questionnaire is 52 and 208 , respectively. Section C comprises of a questionnaire on GSES. There are ten questions, and the overall score ranges between 10 and 40 , with a higher score indicating more self-efficacy. The total score is calculated by finding the sum of all items. The higher the score, the greater the individual's generalized sense of self-efficacy. Instead, the lower the score, the lower the self-efficacy. 


\subsection{Data collection methods}

Ethical approval was granted from all sort of party before the research can proceed. The ethic was first obtained from the Research Ethics Committee, UiTM Shah Alam as well as UiTM Medical Specialist Centre, Sungai Buloh. The data was collected in UiTM Medical Specialist Centre, Sungai Buloh through identifying participants that suit the inclusion and exclusion criteria. The participants were then explained about the study information and asked whether they have the time and want to participate or not. The ones that have agreed with the terms of participating in the study and they were asked to sign their consent before answering the questionnaire to ensure the confidentiality of all the information gathered. The self-administered questionnaire was then given to the participant. In the morning, data collection will be done at the clinics as they are more outpatients rather than in the evening. Usually, outpatient self-answered the questionnaire while waiting for their number to be called at the clinic. The questionnaire then will be collected back after 30 minutes once they finished answering the questionnaire. Whereas in the evening, as the number of outpatients is little, data collection is done to the patient in the ward. As inpatient is weak and sick, and some of them were having an operation, they are assisted while answering the questionnaire. We usually stay beside the patient to help them answering the questionnaire. The data collection was done for at least eight weeks, and 218 questionnaires of participants were successfully collected. The major obstacle that was encountered in this research study was the difficulty in answering questions. The questionnaires used in this study is too many which has an overall total of 64 questions and not suitable for the older adult as they may have become bored and disinterested and they may be answer the questions as $100 \%$ of the participants in this study was older adults ages 60 and above. Moreover, this type of questionnaires is unsuitable for chronic illness patient because they may be feels disturbed. Besides, these participants may have different belief, behaviour and a certain extent of emotion towards the questionnaires presented.

\subsection{Statistical analysis}

Complete questionnaires were analyzed by using IBM Statistical Package for the Social Sciences (SPSS) for windows version 21.0. The descriptive analysis method is used to test and analyze the level of self-efficacy and health-promoting behaviour. Spearman's coefficient of correlation is used to determine the relationship between self-efficacy and health-promoting behaviour.

\subsection{Findings}

\subsection{Demographic data}

The demographic data for this study is shown in Table 1, including gender, age, marital status and type of chronic illness of participants. A total of 218 participants was involved in this study. According to the results, $57.3 \%$ of participants are males, while $42.7 \%$ are females. Mean age of participants was $65.29(5.4)$, which the highest frequency of which $83.0 \%$ belongs to the age group between $60-69$ years old while the lowest rate pertains to the age group between $80-89$ years old with $0.5 \%$ and the maximum age is 92 years old. $95.9 \%$ of the participants are married, while only $4.1 \%$ were single. The total mean score of chronic illness is $0.29(0.13)$.

Table 1. Frequency and Percentage of Demographic Characteristic $(n=218)$

\begin{tabular}{|c|c|c|c|}
\hline Characteristic & Frequency (n) & Percentage (\%) & Mean (SD) \\
\hline \multicolumn{4}{|l|}{ Gender } \\
\hline Male & 125 & 57.3 & \\
\hline Female & 93 & 42.7 & \\
\hline Age of participant & & & $65.29(5.4)$ \\
\hline $60-69$ & 181 & 83 & \\
\hline $70-79$ & 34 & 15.6 & \\
\hline $80-89$ & 1 & 0.5 & \\
\hline $90-99$ & 2 & 0.9 & \\
\hline \multicolumn{4}{|l|}{ Marital status } \\
\hline Married & 209 & 95.9 & \\
\hline Single & 9 & 4.1 & \\
\hline Chronic Illness & 128 & 58.7 & $0.29(0.13)$ \\
\hline Diabetes Mellitus & 162 & 74.3 & \\
\hline Hypertension & 118 & 54.1 & \\
\hline Heart disease & 14 & 6.4 & \\
\hline Arthritis & 5 & 2.3 & \\
\hline COPD & 6 & 2.8 & \\
\hline Stroke & 19 & 8.7 & \\
\hline Asthma & & & \\
\hline
\end{tabular}

\subsection{Level of self-efficacy}

Results from descriptive statistics of the self-efficacy in this study show that the mean and standard deviation of the GSES are 30.6 and 2.84 , respectively. 


\subsection{Level of health-promoting behaviour}

Results from descriptive statistics show that the total average score for the HPLP-II for all 218 participants is 149.07(17.78). The highest mean score is interpersonal relationship subscale with mean of 27.91(3.39). Spiritual growth subscale with mean score 27.65(3.45) is reported as the second highest. Meanwhile, the lowest mean score in physical activity subscale with mean of 18.41(4.81).

\subsection{Relationship between self-efficacy and health-promoting behaviour}

Results from Spearman's coefficient of correlation shown in Table 2 that there is a positive correlation between self-efficacy and the health promotion behaviours of older adults, which is statistically significant, (rho $=0.28, p=0.001$ ) with a significant set of $p<0.05$. The result also shows a statistically significant relationship between self-efficacy and all subscales of HPLP which is health responsibility (rho $=0.27, p=0.001$ ), physical activity (rho $=0.21, p=0.002$ ), spiritual growth (rho $=0.26, p=0.001$ ), interpersonal relationship (rho=0.14, $p=0.04$ ), stress management ( $r h o=0.26, p=0.001$ ), however, subscale nutrition does not show a correlation to the self-efficacy which was, (rho=0.075, $p=0.27$ ). In conclusion, the higher level of self-efficacy among older adult, the higher level of health-promoting behaviour older adult were performed.

Table 2. Relationship between self-efficacy and health-promoting behaviour

\begin{tabular}{|c|c|c|}
\hline \multirow[b]{2}{*}{ Variables } & \multicolumn{2}{|c|}{ Self-efficacy } \\
\hline & Statistical coefficient & $p$-value \\
\hline Health-promoting behaviour & 0.28 & 0.001 \\
\hline Health responsibility & 0.27 & 0.001 \\
\hline Physical activity & 0.21 & 0.002 \\
\hline Nutrition & 0.075 & 0.27 \\
\hline Spiritual growth & 0.26 & 0.001 \\
\hline Interpersonal relationship & 0.14 & 0.04 \\
\hline Stress management & 0.26 & 0.001 \\
\hline
\end{tabular}

\subsection{Discussion}

\subsection{Level of self-efficacy}

This study revealed that older adults with chronic illness have higher self-efficacy. According to the score, older adults exercise good health behaviour to maintain their wellness. The study findings indicated that older adult has a high score in GSES, which was 30.6 considered high. In general, this finding revealed that older adult with chronic illness has a higher self-efficacy. According to the score, older adult exercising good health-promoting behaviour to maintain their wellness. In a study by Omu and Reynolds (2013), entitled 'Life satisfaction and self-efficacy in patients affected by a first stroke', their mean GSE was 31.7(7.5) whereas a study by Grill, Schaffler, Huppert, Muller, Kapfhammer, and Brandt (2014), had a mean GSES score of 31.8 (SD = 4.3).

\subsection{Level of health-promoting behaviour}

This study found a moderate level of HPLP-II behaviours. The participant has a moderate level of health-promoting behaviour, which was 149.07. The result is consistent with the previous study by Wu, Chen, Cho and Chiou (2016). Health-promoting behaviour among older adult needs to be in a moderate level or for the best result; it is good if at a high level. Other than that, this study reported that spiritual growth and the interpersonal relationship has the highest score and physical activity has the lowest score in the health-promoting behaviour subscales. This finding was the same reported in the study by Wu et al. (2016).

Physical activity, which measures the older adult ability to follow a regular exercise pattern, was ranked last among the healthpromoting behaviours in this study. Low physical activity may due to limitation because of their chronic illness. Another potential reason was because of a lack of knowledge regarding the importance of exercise to their body. Health-promoting behaviour among older adult needs to be in a moderate level or for the best result, it is good if at a high level. As one grows older, health-promoting behaviour is essential to practice preventing a negative effect on health. Low level of health-promoting behaviour may lead to low quality of life. Other than that, this study reported that spiritual growth and the interpersonal relationship has the highest score and physical activity has the lowest score in the health-promoting behaviour subscales.

\subsection{Relationship between self-efficacy and health-promoting behaviour}

This study revealed that there were statistically significant between self-efficacy and health-promoting behaviour. This suggests that self-efficacy in older adult strongly influenced the health-promoting behaviour towards their chronic illness. A previous study supported 
and agreed with the researcher's finding whereby there was a relationship between self-efficacy and health-promoting with behaviour. A similar pattern of results was obtained in the study by (Yeom, 2015; Giena, Thongpat, \& Nitirat, 2018) that patient with hypertension that has a good self-efficacy can cope with their illness well. The result revealed that self-efficacy has strongly affected health-promoting behaviour among older adult with chronic illness. An older adult with high self-efficacy has confidence in performing healthy behaviour in achieving the quality of life.

There is a relationship between self-efficacy and subscale of health-promoting behaviour except for nutrition. However, numerous studies showed a strong correlation between self-efficacy and all subscale of health-promoting behaviour (Abdolkarimy, Zareipour, Mahmoodi, Dashti, Faryabi, \& Movahed, 2017). Next, a study by Huffman, Pieper, Hall, Clair, and Kraus (2014) in their research discovered that self-efficacy for exercise associated with physical activity between rheumatoid arthritis patients. Prince et al. (2014) found that low self-efficacy related to the low level of physical activity. According to the findings of the previous study, however, found that physical activity was correlated with a belief about physical activity only and not associated with person self-efficacy (Larkin, Gallagher, Fraser, \& Kennedy, 2016). The previous study by Dekker, Dijk, \& Veenhof (2009) stated that patient with hip arthritis has a risk of functional decline if their self-efficacy decrease. Self-efficacy positively associated with physical activity. (Daniali, Darani, Eslami, \& Mazaheri, 2017; Martin et al., 2008). A study by Roddenberry and Renk (2010) found that people with a higher level of stress have lower self-efficacy and a higher level of chronic illness. In conclusion, many studies have shown a significant correlation between selfefficacy with HPLP and its subscale. It is important to highlight the fact that self-efficacy bring a greater impact on individual life towards a great and healthy future.

\subsection{Conclusion \& recommendations}

The level of self-efficacy between an older adult with chronic illness can be made better with proper awareness and intervention. Selfefficacy is one of an important factor for an older adult to maintain health and improve quality of life to preserve their daily living with better health-promoting behaviour despite the illness that they are having. Nursing interventions are needed to increase the level of selfefficacy among older adult patient. The interventions should focus on how to maintain quality of life. Not just nursing care that needs to be administered, an education about self-efficacy also should be concerned to promote good health-promoting behaviour.

The importance of self-efficacy has been proven to affect health-promoting behaviour among older adults in managing their chronic illness towards the quality of life. Considering the findings of the present study, and regarding the role of health-promoting behaviours and self-efficacy, which impaired the quality of life of the patients. It is recommended for health care practitioners to produce interventions that can increase the level of self-efficacy, which at the same time, improve health-promoting behaviour. Further research about selfefficacy and health-promoting behaviour should be done with a larger population and longer duration of time so that the study can gather more information thus more accurate results.

\section{Acknowledgements}

The author wishes to acknowledge Universiti Teknologi MARA (UiTM), Centre for Nursing Studies, Faculty of Health Sciences UiTM, and UiTM Medical Specialist Centre, Sungai Buloh for their support. The authors are grateful to thank Puteri NurFarah Hanan binti Razak for her invaluable contribution in this study.

\section{References}

Abdolkarimy, M., Zareipour, M., Mahmoodi, H., Dashti, S., Faryabi, R., Movahed, E. (2017). Health Promoting Behaviors and their Relationship with Self-efficacy of Health Workers. Iran Journal of Nursing.30 (105):68-79.

Bandura, A. (1994). Self-efficacy. In V. S. Ramachaudran (Ed.), Encyclopedia of human behavior (Vol. 4, pp. 71-81). New York: Academic Press.

Bandura, A. (1997). Self-efficacy: The exercise of control. New York, NY, US: W H Freeman/Times Books/ Henry Holt \& Co., Doyle, Y., Mckee, M., Rechel, B., \& Grundy, E. (2009). Meeting the challenge of population ageing. Bmj, 339(Oct05 1). doi:10.1136/bmj.b3926

Chenary, R., Noroozi, A., Tavafian, S. S., \& Firoozabadi, M. S. (2016). Effective Factors on Health-Promoting Lifestyle Among Iranian Chemical Veterans in 2014 Based on Health Promotion Model: A Path Analysis. Iranian Red Crescent Medical Journal, 18(8). doi:10.5812/ircmj.33467

Daniali, S.S., Darani, F.M., Eslami, A.A., Mazaheri, M. (2017). Relationship between Self-efficacy and Physical Activity, Medication Adherence in Chronic Disease Patients. Adv Biomed Res. 2017 May 29;6:63. doi: 10.4103/2277-9175.190997. eCollection 2017. PubMed PMID: 28603704; PubMed Central PMCID: PMC5458405.

Dekker, J., Dijk, G. M., \& Veenhof, C. (2009). Risk factors for functional decline in osteoarthritis of the hip or knee. Current Opinion in Rheumatology, 21 (5), $520-524$. doi:10.1097/bor.0b013e32832e6eaa

Giena, V. P., Thongpat, S., \& Nitirat, P. (2018). Predictors of health-promoting behaviour among older adults with hypertension in Indonesia. International Journal of Nursing Sciences. doi:10.1016/j.jinss.2018.04.002

Grill, E., Schäffler, F., Huppert, D., Müller, M., Kapfhammer, H.-P., \& Brandt, T. (2014). Self-Efficacy Beliefs Are Associated with Visual Height Intolerance: A CrossSectional Survey. PLOS ONE, 9(12), e116220. http://doi.org/10.1371/journal.pone.0116220 
Huffman, K. M., Pieper, C. F., Hall, K. S., Clair, E. S., \& Kraus, W. E. (2014). Self-efficacy for exercise, more than disease-related factors, is associated with objectively assessed exercise time and sedentary behaviour in rheumatoid arthritis. Scandinavian Journal of Rheumatology, 44(2), 106-110. doi:10.3109/03009742.2014.931456

Larkin, L., Gallagher, S., Fraser, A. D., \& Kennedy, N. (2016). Relationship between self-efficacy, beliefs, and physical activity in inflammatory arthritis. Hong Kong Physiotherapy Journal,34, 33-40. doi:10.1016/j.hkpj.2015.10.001

Mishali, M., Omer, H., Heymann, A.D. (2011). The importance of measuring self-efficacy in patients with diabetes. Fam Pract. 2011 Feb;28(1):82-7. doi: 10.1093/fampra/cmq086. Epub 2010 Nov 3. PubMed PMID: 21047940.

Mofrad, Z. P., Jahantigh, M., \& Arbabisarjou, A. (2016). Health Promotion Behaviors and Chronic Diseases of Aging in the Elderly People of Iranshahr*- IR Iran. Global Journal of Health Science, 8(3), 139-145. http://doi.org/10.5539/gjhs.v8n3p139

Omu, O., \& Reynolds, F. (2013). Life satisfaction and self-efficacy in patients affected by a first stroke living in Kuwait: A two-phase study. Physiotherapy Theory and Practice, 29(6), 443-456. doi:10.3109/09593985.2012.752057

Prince, S. A., Reed, J. L., Nerenberg, K. A., Kristjansson, E. A., Hiremath, S., Adamo, K. B., Reid, R. D. (2014). Intrapersonal, social and physical environmental determinants of moderate-to-vigorous physical activity in working-age women: A systematic review protocol. 3(1). doi:10.1186/2046-4053-3-132

Quinn, C.C., Khokhar, B., Weed, K., Barr, E., Gruber-Baldini, A.L. (2015). Older Adult Self-Efficacy Study of Mobile Phone Diabetes Management. Diabetes Technol Ther. 2015 Jul;17(7):455-61. doi: 10.1089/dia.2014.0341. Epub 2015 Feb 18. PubMed PMID: 25692373; PubMed Central PMCID: PMC4808269.

Roddenberry, A. K., Renk. (2010). "Locus of Control and Self-Efficacy: Potential Mediators of Stress, Illness, and Utilization of Health Services in College Students." Child Psychiatry and Human Development 41 (4): 353-370. doi:10.1007/s10578-010-0173-6.

Scult, M., Haime, V., Jacquart, J., Takahashi, J., Moscowitz, B., Webster, A., Denninger, J.W., Mehta, D.H. (2015). A healthy aging program for older adults: effects on self-efficacy and morale. Adv Mind Body Med. 2015 Winter;29(1):26-33. Review. PubMed PMID: 25607120; PubMed Central PMCID: PMC4437657.

Ward, B. W., Schiller, J. S., \& Goodman, R. A. (2014). Multiple Chronic Conditions among US Adults: A 2012 Update. Preventing Chronic Disease 11.doi:10.5888/pcd11.130389

World Health Organization, Global status report on non-communicable diseases 2010 (2011). Retrieved from http://www.who.int/nmh/publications/ncd_report_full_en.pdf

Wu, T., Chen, I., Cho, S., \& Chiou, A. (2016). The Relationship Between Health-Promoting Behaviors and Metabolic Syndrome in Community-Dwelling Older Adults. Biological Research for Nursing, 18(5), 549-557. doi:10.1177/1099800416655882

Yeom, H. (2015). Illness Representations, Self-Efficacy, And Health-Promoting Behaviors in Older Hypertensive Patients. The Gerontologist,55(Suppl_2), 77-77. doi:10.1093/geront/gnv449.21 